\title{
The 74-inch Reflecting Telescope for the University of Toronto
}

SINCE November 1930, a 74-in. reflecting telescope-the largest in the British Empire and the second largest in the world-has been under construction for the University of Toronto at the works of Sir Howard Grubb, Parsons and Co., Newcastle-upon-Tyne, a subsidiary company of Messrs. C. A. Parsons and Co., Ltd. The observatory will be situated in a park of 177 acres on Richmond Hill, eight hundred feet above sealevel, a few miles to the north of Toronto, and, in addition to the 74-in. reflector and its dome, will comprise a block of administration buildings on which three smaller domes will be mounted. It is being built as a memorial to the late David A. Dunlap, the funds being provided by his widow and son, and, on completion, will be presented to the University of Toronto and administered by the Department of Astronomy.

The telescope is of the reflecting type with a clear aperture of 74 in. and is arranged so that it can be used either as a Cassegrain or Newtonian (Fig. 1). The mounting is of the modified 'English' or 'Composite' type, in which the tube is placed on one side of the polar axis and the counterpoise on the opposite side.

\section{The Mounting}

The polar axis is $22 \mathrm{ft}$. long, built up of two tapered tubular steel castings with forged steel pivots shrunk into the ends and bolted to a central cubical steel box. It runs in self-aligning radial ball bearings with ball thrust bearing at the lower end housed in a cast iron base casting. The weight of the axis is nine tons. The bearing housing at the upper, or North, end is fitted with adjustments for the true alignment of the axis.

The driving circle, or wormwheel, is mounted free on ball bearings on the lower pivot of the axis and can be clamped rigidly to the quick motion gear wheel, which is keyed to the axis, by a motor operated clamping gear. The circle is a steel casting and the bronze rim, in which the teeth are cut, is slightly shrunk on and fixed with a number of delta metal screws. The pitch diameter is $8 \mathrm{ft}$., cut into 960 teeth of $8 \mathrm{~mm}$. circular pitch. The wheel was copied from a $4 \mathrm{ft}$. diameter master circle graduated on silver.

The sidereal circle is $8 \mathrm{ft}$. diameter and is strung on the boss of the driving circle. It can easily be rotated by any one of six handwheels attached to it and fitted with pinions gearing into a toothed ring attached to the driving circle. It is constructed of fabricated steel with a delta metal rim 3 in. wide graduated on both edges to 1 minute of time divisions. The lower set of divisions

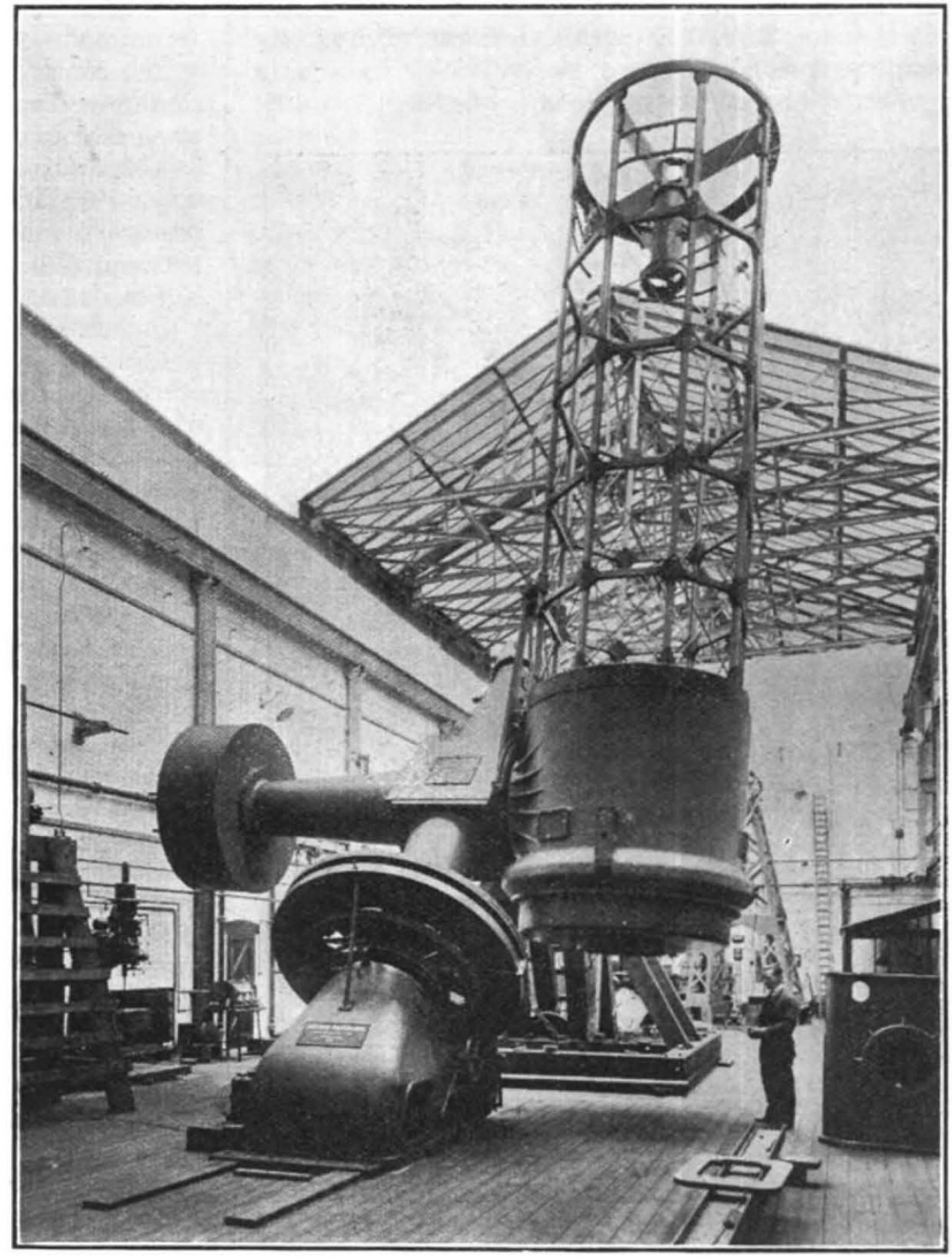

FIG. 1. The Toronto 74-in. reflector. View from so:th-cast.

read against indexes fixed to the guard of the driving circle and mark sidereal time, while the upper set of divisions read against indexes attached to the polar axis and mark right ascension.

An hour angle circle is fixed to the quick motion gear wheel. The declination axis passes through the cubical centre section of the polar axis at right angles, supported at the outer end in a tubular tapered steel casting attached to the cubical portion of the polar axis.

The declination axis itself is of forged steel $13 \mathrm{ft}$. long, weighing $3 \frac{1}{2}$ tons and formed with a flange 
at the inner end $3 \mathrm{ft} .5 \mathrm{in}$. diameter, to which the tube is attached. It is mounted in ball radial bearings, with a double thrust bearing at the small, or outer, end, to which is keyed the quick motion gear wheel and also the declination circle $6 \mathrm{ft} .3 \mathrm{in}$. diameter, graduated to $1^{\circ}$ of arc. The gear wheel and circle are housed inside a drum-shaped casting attached to the end of the tubular support carrying the axis, this casting forming the counterpoise for the tube. The declination circle drives two drums 12 in. diameter, geared up $72: 1$, and arranged so that there is no backlash. These drums are graduated to 60 divisions, each division indicating 5 minutes of arc. The tube comprises three sections,

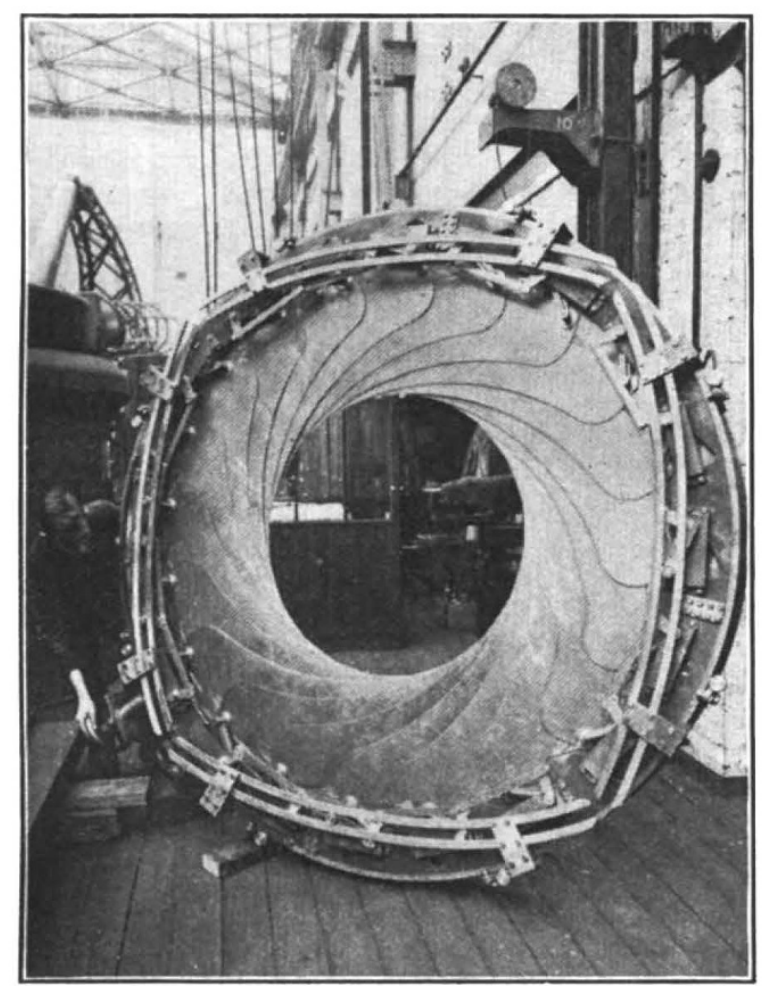

FIG. 2. The iris diaphragm. Half-aperture.

the lower portion a cell in which the main mirror is mounted, the central section which is bolted to the flange of the declination axis, and the upper, or skeleton, section for carrying the Cassegrain or Newtonian mirrors and the photographic breechpiece.

The main mirror cell is a ribbed steel casting fitted with nine circular pads for the back support of the mirror. The pads are mounted in groups of three on spherical seatings on three triangles, which are themselves mounted on ball-ended screws, by which the mirror can be 'squared'. The nine pads are so disposed that each bears its proper proportion of the load.

For the lateral support of the mirror, 18 weighted levers are disposed round the inside of the cell mounted on universal joints, the short end of the levers engaging in holes in brackets riveted to a flexible band loosely clamped round the mirror.
This band has blocks fixed at intervals on its inner edge, loosely fitting into a groove in the edge of the mirror to keep it central. A large wormwheel is fitted to the back of the cell for carrying the spectrograph.

The centre section of the tube is a steel casting $7 \mathrm{ft}$. diameter weighing $5 \frac{1}{2}$ tons, and formed with a large boss on one side for attachment to the flange of the declination axis. Just above the lower flange, to which the cell is attached, the casting is swelled out to $8 \mathrm{ft}$. $7 \mathrm{in}$. diameter to accommodate an iris diaphragm (Fig. 2).

The construction of this diaphragm is generally similar to those used in cameras, but in order to prevent sag, due to the considerable weight of the leaves, and to keep the aperture central when the tube is in the horizontal position, it has been found necessary to guide the moving ends of the leaves between radius bars. The range of the diaphragm is from 12 to 74 inches aperture and is operated by a handwheel.

The upper, or skeleton, portion of the tube is octagonal in section, the main and cross members of which are constructed of 3 -in. duralumin I beams, connected by steel gussett plates. Diagonal tension rods of duralumin, screwed with right and left hand threads, are fitted in each bay and tightened up to a predetermined tension, so that they are always in tension, whatever the position of the tube.

A fabricated steel box of square section, with circular flanges, is suspended in the centre of the upper end of the tube on four spring steel strips placed edgeways, to which the mountings for either the Cassegrain or Newtonian mirrors can be attached. Gear is supplied for handling these mountings and interchanging them conveniently and safely. The Newtonian mirror is arranged so that the reflected beam can be directed to any one of four positions round the sides of the tube, where frames are fixed to which the photographic breechpiece can be attached. This breech-piece comprises a focusing gear and plate holder with two guiding microscopes mounted on cross slides operated by micrometer screws. It is fitted also with a rotary motion to correct for rotation of the field. The plate holders take plates $3 \frac{1}{4}$ in. $\times 4 \frac{1}{4}$ in. and are interchangeable with a knife-edge focusing plate and with adapters for oculars.

The driving clock comprises a heavy crossed arm governor driven indirectly by a $\frac{1}{2}$ horse power direct-current motor through a differential gear box. A weight suspended from a chain passing over a pulley and attached to the outside of the differential gear box gives a constant driving force to the governor. The gear box carries an arm with a contact at its outer end passing over a number of studs arranged concentrically and connected to resistances in the field circuit of the motor. When the motor is running at a correct speed, the weight is kept floating, but if its speed alters, the gear box rotates together with the contact arm, which immediately corrects the speed of the motor by altering the field resistance. The governor runs at 
80 r.p.m. and is directly coupled to a worm gearing into a wormwheel on a jack shaft making one revolution in $\mathbf{2 4}$ seconds. The jack shaft is mounted parallel to the shaft on which the driving worm is cut and geared to it by a pair of accurately cut spur gears. Thus there are only one pair of spur gears and one worm wheel between the clock governor and the driving screw.

A 'Grubb' type of electrical control operated by one of the observatory clocks, is incorporated on the jack shaft.

The right ascension and declination quick motions are operated by $1 \frac{1}{4}$ and $\frac{3}{4}$ horse-power reversible motors respectively and are arranged to rotate the axes at the rate of one revolution in eight minutes. The drives are taken through dog clutches operated by solenoids in parallel with the motor circuits, so that the motors and reduction gears are automatically disconnected from the telescope when not in use. A friction clutch is also incorporated and the switch gear controlling the motors so arranged that when the motors are switched off the dog clutches remain engaged for a few seconds, allowing the friction clutches to slip and bring the telescope to rest.

The declination clamp is placed between the tube and the polar axis, and consists of a fabricated steel arm about $7 \mathrm{ft}$. long mounted on a ' $\mathrm{V}$ ' ring 4 -ft. diameter attached to the side of the polar axis. This arm can be rigidly clamped to the ' $V$ ' ring by a toggle gear operated by a small electric motor. The outer end of the arm carries a nut mounted on a link motion and engages with a screw mounted in bearings attached to a bracket which is firmly clamped to the side of the tube. A motor operated two speed gear is connected to this screw for giving the setting and guiding motion in declination. This motor is controlled by two separate reversing switches. For the setting motion a dog clutch operated by a solenoid in parallel with the motor connects the gear to the slow motion screw and moves the tube in declination through 15 minutes of arc in one minute of time. For the guiding motion an electromagnet in parallel with the motor brings a differential gear into action, giving a rate of motion of 30 seconds of are in one minute of time. Similar rates of motion are provided for setting and guiding in right ascension.

Three finders are provided, one of $4 \frac{1}{2}$ in. aperture with eyepiece mounted on cross slides, at the lower end of the tube, one of $2 \frac{3}{4}$ in., and one of $2 \mathrm{in}$. aperture at the upper end.

\section{Optical Parts}

The main parabolic mirror, of pyrex glass, will have a focal length of $30 \mathrm{ft}$. The Cassegrain and Newtonian mirrors, of hard crown, are of 19 and 20 in. diameter respectively, the former being designed to give an equivalent focal length of $111 \mathrm{ft}$. $(F / 18)$.

The total weight of the telescope is about 50 tons.

The stellar spectrograph is being constructed by Messrs. Adam Hilger, Ltd. It is of the single prism type with $2 \frac{3}{4}$ in. collimator and two cameras of $12 \frac{1}{2} \mathrm{in}$. and $25 \mathrm{in}$. focus respectively.

\section{The Dome}

The steel dome is $61 \mathrm{ft}$. outside diameter, with parallel opening $15 \mathrm{ft}$. wide extending from the horizontal to $7 \mathrm{ft}$. beyond the zenith. Two parallel moving shutters running on rails at the top and bottom of the dome close the opening and are operated simultaneously by means of wire ropes connected to a motor operated gear. An emergency hand gear is also provided. Two motor operated wind screens of sail cloth are mounted in the opening, one rising from the bottom, the other descending from the top.

The dome, which weighs about 80 tons, is carried on 24 canted rollers of $27 \mathrm{in}$. diameter mounted in self-aligning ball bearings and running on a flat bottomed rail. Sixteen pairs of lateral roller bearings on the inner and outer edge of the rail keep the dome in position. Two segmental platforms, the lower one at the base of the opening, the upper one at the back at a 16 -ft. higher level, are fixed inside the dome. Rails are mounted on the parallel straight edges of these platforms on which runs a bridge in the form of a semi arc. This bridge is $5 \mathrm{ft} .6$ in. wide, and divided into two portions, the right hand side forming a stairway, the left being a track on which a truck carrying the Newtonian observing platform runs. The upper portion of the truck is automatically kept horizontal as it travels up the curve of the arch, by means of a lever, the outer end of which travels on a contoured rail. The truck is operated by means of a motor driven winding drum fixed at the top of the bridge, where is also fixed the gear for giving it the cross traverse motion. The rail on which the dome runs is mounted on a strong annular girder on the top of 24 steel pillars, $21 \mathrm{ft}$. high. The pillars form a circular building, sheathed inside and out with steel sheeting.

The entrance is in the south side through a steel porch with two pairs of doors. The observing floor is $13 \mathrm{ft}$. above ground level with doorway leading on to the top of the porch. From each side of the porch a stairway gives access to a gallery running right round the building $23 \mathrm{ft}$. above the ground. A similar gallery on the inside of the building gives access to the lower segmental platform in the dome and so on to the Newtonian observing platform.

A lift is provided inside the circular building for removing the cell and main mirror when it requires to be resilvered. The $7 \frac{1}{2}$ horse-power motor and gear for rotating the dome will be fixed at ground level in the building.

Rotation is effected by means of an endless steel rope passing almost round an annular channel ring carried on brackets fixed to the base of the dome, over two tangent pulleys and down to the turning gear, a tension pulley being provided for keeping the rope tight.

The dome and building was dispatched in June and the telescope has recently been shipped. 